\title{
Economic empowerment of women in the informal African craft industry: The case of Tembisa
}

\begin{tabular}{|c|c|}
\hline \multicolumn{2}{|c|}{$\begin{array}{l}\text { Authors: } \\
\text { Louisa D. Jokia }^{1,2} \text { (D) } \\
\text { Elana Swanepoel }^{2} \text { (D) } \\
\text { Marius Venter }{ }^{1} \text { (D) }\end{array}$} \\
\hline \multicolumn{2}{|c|}{$\begin{array}{l}\text { Affiliations: } \\
{ }^{1} \text { School of Economics, College } \\
\text { of Business and Economics, } \\
\text { University of Johannesburg, } \\
\text { Johannesburg, South Africa }\end{array}$} \\
\hline \multicolumn{2}{|c|}{$\begin{array}{l}{ }^{2} \text { Centre for Local Economic } \\
\text { Development, College of } \\
\text { Business and Economics, } \\
\text { University of Johannesburg, } \\
\text { Johannesburg, South Africa }\end{array}$} \\
\hline \multicolumn{2}{|c|}{$\begin{array}{l}\text { Corresponding auth } \\
\text { Marius Venter, } \\
\text { mventer@uj.ac.za }\end{array}$} \\
\hline \multicolumn{2}{|c|}{$\begin{array}{l}\text { Dates: } \\
\text { Received: } 02 \text { May } 2020 \\
\text { Accepted: } 11 \text { Sept. } 2020 \\
\text { Published: } 07 \text { Jan. } 2021\end{array}$} \\
\hline \multicolumn{2}{|c|}{$\begin{array}{l}\text { How to cite this article: } \\
\text { Jokia, L.D., Swanepoel, E. \& } \\
\text { Venter, M., 2021, 'Economic } \\
\text { empowerment of women in } \\
\text { the informal African craft } \\
\text { industry: The case of } \\
\text { Tembisa', Journal of Economic } \\
\text { and Financial Sciences 14(1), } \\
\text { a578. https://doi.org/ } \\
\text { 10.4102/jef.v14i1.578 }\end{array}$} \\
\hline \multicolumn{2}{|c|}{$\begin{array}{l}\text { Copyright: } \\
\text { (c) 2021. The Authors } \\
\text { Licensee: AOSIS. This } \\
\text { is licensed under the } \\
\text { Creative Commons } \\
\text { Attribution License. }\end{array}$} \\
\hline \multicolumn{2}{|l|}{ Read online: } \\
\hline aryin: & $\begin{array}{l}\text { Scan this QR } \\
\text { code with your } \\
\text { smart phone or } \\
\text { mobile device } \\
\text { to read online. }\end{array}$ \\
\hline
\end{tabular}

Orientation: In Tembisa, within the Ekurhuleni Metropolitan Municipality, women sell woven baskets and traditional beaded accessories, trading informally. The baskets have both functional and aesthetic values, as they are used for interior decoration. The skill of weaving is passed on from generation to generation.

Research purpose: To investigate the business model used, the skills needed and the opportunities and support measures available to these craft traders to empower them to transition from being informal traders to becoming formal craft traders.

Motivation for the study: Little is known about the women who sell crafts informally in Tembisa. The literature has revealed that the majority of informal traders in South Africa are women from poor communities. It is not known whether opportunities, support measures and sources of funding are available in the local municipality and community to assist these craft traders in transitioning from the informal to the formal sector.

Research approach/design and method: A mixed-methods research approach was adopted. A quantitative survey using a structured questionnaire enabled data collection from 32 traders. Through in-depth interviews, information on current programmes by the Ekurhuleni Metropolitan Municipality and the Moses Molelekwa Centre were obtained.

Main findings: This research revealed that the African craft business is seasonal, depending on the supply of weaving material and cultural and other functions. Most of the traders were not South African and were not interested in transitioning from the informal to the formal sector. Both the municipality and the centre offered programmes to assist informal traders to transition from the informal to the formal sector.

Practical/managerial implications: Only a few of the respondents were South African. It is essential to ensure that the skill of weaving continues and be elevated to lucrative business. Owing to the fact that informal businesses purchase from formal business, government programmes should focus more on supporting informal business to be successful without requiring them to be formalised.

Contribution/value-add: The business model of the craft traders in Tembisa has been unpacked. Insight has been gained into their economic challenges and the measures that a local authority could implement to empower and assist these women.

Keywords: African craft; Ekurhuleni Metropolitan Municipality; empowerment; informal craft traders; local economic development.

\section{Introduction}

This article falls in the sphere of local economic development (LED). There are various definitions for LED, but for the purpose of this article the definition of Swinburn, Goga and Murphy (2006) is used:

$[L] E D$ occurs when a community consciously decides to improve the economy of the area where they live, by getting all stakeholders such as the public, private and nongovernmental sector in that specific area to work together using their local assets in a manner that it creates decent jobs which will improve local living conditions ensuring a sustainable economic future. (p. 1)

Venter (2014:722) elucidated that 'It is generally believed that municipalities are the foot-soldiers of local economic development'. Established in 2000, Ekurhuleni Metropolitan Municipality is one of the metros in South Africa. According to the Ekurhuleni Metropolitan Municipality (2017:12), its four previously disadvantaged areas, of which Tembisa is one, are low income residential clusters located on the urban periphery and are far removed from the majority of social 
and economic opportunities in the metropolitan area'. These areas collectively comprise approximately $61 \%$ of the total population of Ekurhuleni, whilst Tembisa has a population of 463109 and a dependency ratio of 32.7\% (Statistics South Africa 2015). The dependency ratio is defined as the number of children (0-14 years) and older persons (65 years and older) per hundred persons of working age (United Nations Conference on Trade and Development (UNCTAD) 2017). These are people who are not part of the labour force.

From driving in the streets of Tembisa, it was observed that several women are informally selling African crafts, particularly woven items and beaded accessories. Although these items seem to be popular and are the type of item that could possibly be traded formally, these women trade informally. The empowerment of these women falls under the National Framework for Local Economic Development (NFLED) 2017-2022, Policy Pillar 2: Developing inclusive economies (Department of Co-operative Governance and Traditional Affairs (CoGTA) 2017:43-44). The CoGTA (2017:6) maintains that inclusive economic growth 'creates opportunities for all segments of the population and distributes dividends of increased prosperity in both monetary and non-monetary terms fairly across the society'. The development of inclusive economies includes support for the informal economy, township development and empowerment of the youth and women (CoGTA 2017). Economic empowerment can be defined as an individual's ability to access resources, own resources and control such resources (Brody et al. 2015). Therefore, the main purpose of this article is to investigate the business model used, the skills needed and the opportunities and support measures available to Tembisa craft traders to empower them to transit from being informal traders to becoming formal craft traders.

\section{Background}

The South African Craft Industry (1998) found that black women dominate the craft industry because of fewer barriers to entry. These women could use traditional skills to create crafts, work from home and did not require capital resources to create the crafts (The South African Craft Industry 1998). Even though the craft sector mainly includes unskilled labourers from poor rural areas, it addresses some of the challenges of these communities, such as unemployment (Nyawo \& Mubangizi 2015:03).

The sector creates employment and an entry to the economy for disadvantaged communities. When women are able to receive economic benefits and acknowledgement for their craft, it enhances their independence, and they are able to acknowledge their self-worth (Malema \& Naidoo 2017). It has been shown that craft initiatives or activities could contribute positively to personal health and reduce levels of depression.

Through the Department of Arts and Culture, the South African government supports artists in local communities.
This department has a 5-year strategic plan focusing on the following themes: skills development; economic development; development, preservation and promotion of arts, culture and heritage; preservation of access to information and social cohesion and nation building (Department of Arts and Culture, 2011:16). Moreover, there are more than 160 community art centres that are in operation and offer a range of programmes from general socio-cultural promotion to advanced programmes and vocational training (Department of Arts and Culture 2016:23).

In 2003, the Gauteng Organisation of Community Arts and Culture Centres was established to support the functionality of these community art centres through six focus areas, namely, community art projects, training, lobbying and advocacy, website information systems and links, networking and creating art centres (Gauteng Organisation of Community Arts and Culture Centres 2010). One of the organisation's 160 community art centres, the Moses Molelekwa Community Centre in Tembisa, hosted the Ekurhuleni Public Art Exhibition in 2016. Of the 30 artists displaying works at the centre, 10 were from Tembisa ('Moses Molelekwa Arts Centre hosts arts exhibition' 2016). The research on which this article is based investigated whether this centre can offer any training for informal craft traders in Tembisa and whether they can be empowered to transition from informal trading to formal trading.

The women in Tembisa sell African baskets and traditional beadwork accessories for functional and decorative purposes. According to Anitra Nettleton (2010:55-56), in Johannesburg and other urban centres, baskets are increasingly purchased primarily as decorative items for homes, offices and hotels, and even as collector's items. Popular South African baskets are named ukhamba [shape of a light bulb], isichumo [for carrying water], imbenge [saucer shape], isisquabetho [for carrying grain] and iqutu [for dried herbs] (Ilala Weavers 2018). The African traditional beadwork can be worn as a general fashion accessory, and at cultural functions including at weddings or ancestral family ceremonies. The traditional beadwork skill is passed from one generation to the next (Zungu 2000).

\section{Literature review}

To understand the policy frameworks for empowering women, the following documents are relevant: the National Development Plan 2030, Integrated Development Plan (IDP) and the NFLED (2017-2022). The National Development Plan Vision 2030 (National Planning Commission 2011) highlights the importance of ensuring that those from disadvantaged backgrounds are included in the country's economic growth. Guided by the National Development Plan and the first NFLED (2006-2011) (CoGTA 2009:10), municipalities each formulate their own IDP. In its IDP for 2017/2018 to 2020/2021, the Ekurhuleni Metropolitan Municipality (2017) does not include empowerment plans for women. However, within its fifth strategic objective, which is 'to create an enabling environment for inclusive growth and 
job creation', the municipality emphasises the importance of ensuring that women are amongst those who benefit from the job-creation initiatives developed by the municipality. This means that women will have the opportunity to be part of programmes such as the skills and capability development that is part of the 10-point economic plan for the Ekurhuleni Metropolitan Municipality (2017:227-228).

Guidelines for stakeholder contribution to LED were provided in the NFLED from inception (2006-2011) to the latest edition (2017-2022) (CoGTA 2017:30). The NFLED has six core policy pillars, and the study on which this article is based falls in the second pillar, which focuses on developing inclusive economies (CoGTA 2017:29). The development of inclusive economies would include the empowerment of women, in particular those in the informal sector, assisting them to transition from the informal to the formal economy. The Department of Trade and Industry (DTI) has noted that women continue to be relegated from the mainstream of the economy, despite resources having been allocated to their economic empowerment, and identified a need to substantially increase the participation of and to improve the support for women and youth engaged in or who want to engage in business ventures in South Africa (CoGTA 2009:46).

The economic empowerment of women would contribute to LED, which has as central theme the creation of jobs. A jobcreation plan could include activities as follows: 'mentorship programmes, public works programmes, intensive technical and business skills training, development of incubators and job centres, and youth development programmes' (Meyer 2014:14). Development at the local sphere of government is essential, as this is the ground level where citizens' participation is high.

One of the guiding principles of LED emphasises: 'People are the single greatest resource and including all citizens in development and increasing their skills leads to increased opportunities for stimulating local economies' (Rogerson 2009:18-19). Investing in the skills development of the informal craft traders in Tembisa could stimulate the local economy, as it may lead to the growth of their businesses.

In 2006, the DTI (2006) developed a strategic framework that focuses on gender and women's economic empowerment. The framework highlighted the importance of women being empowered socially, economically and politically. The framework has seven programme initiatives. Of these, the entrepreneurial education, training and skills development could be said to be one of the most relevant to the women in Tembisa.

In 2014, the DTI launched the National Informal Business Upliftment Strategy (Nibus). A collaboration initiative between government, the private sector and nongovernmental organisations, Nibus aimed to increase the support and training of informal traders and was estimated to benefit more than 2 million informal businesses in South Africa (Fredericks 2014). The first of two phases, the shared economic infrastructure facility covers funding of infrastructure shared by the informal traders in Gauteng, Mpumalanga, Western Cape and Eastern Cape (Fredericks 2014). The second phase, the informal business upliftment facility (Fredericks 2014):

$[W]$ ill prioritise women, youth and people with disabilities who own businesses based in townships, rural areas and the inner city with skills development, promotional material, product improvement, technology support, equipment and help with basic compliance such as registration for business and tax. (p. 1)

The informal women craft traders in Tembisa could benefit from the Nibus initiative.

The Department of Small Business Development's Informal and Micro Enterprise Development Programme (IMEDP) provides financial support for informal businesses (DSBD 2017). The IMEDP offers a $100 \%$ grant up to R80 000 to informal and microenterprises with turnovers ranging from R1000 to R200 000 to assist them in improving their competitiveness and sustainability to become formal business (DSBD 2017:28). According to the Department of Small Business Development, the 'upliftment programmes will result in informal businesses realising the benefits of transitioning; where they will be able to benefit from the incentives and small medium enterprises programmes' (DSBD 2017:39).

South Africa's informal sector is growing as a result of the increasing unemployment rate in the country (McLachlan 2005). It is dominated by women, as men tend to be absorbed into the formal sectors, such as mining and manufacturing (McLachlan 2005). The informal sector includes 'economic activities that are not monitored by government and are not included in the gross national product' (CoGTA 2017:6). These informal businesses are not registered with municipal databases, as they are not formally registered, and generally do not pay tax. Consequently, they do not receive support from the local government.

The majority of craft businesses in South Africa operate in the informal sector (Nyawo \& Mubangizi 2015). In 2013, the size of South Africa's informal sector was estimated to be approximately R157 billion with about 300000 of the population involved in the informal economy (Ndabeni \& Maharaj 2013). In comparing the informal sector with other economic sectors of the country, it was found to be 2.5 times the size of the agricultural sector and approximately $70 \%$ the size of the mining sector (Ndabeni \& Maharaj 2013). In the informal sector, street vending is a dominant activity. In 2007, of more than 500000 street vendors in informal employment, approximately 360000 were women (Cohen \& Horn 2012:6). This indicates that women dominate the informal sector. Chen (2012:12) argued that there is a link between the formal and informal sector, as most of the informal businesses purchase materials from the formal 
businesses. Several factors contribute to the growth of the informal sector (Ndabeni \& Maharaj 2013):

[I]ncreased urbanisation of blacks; slow pace of economic growth; incidence of jobless growth; decreased incidence of formal employment; promotion of small, medium and micro enterprises (SMMEs); informalisation of formal businesses; costs and regulatory barriers of entry into the formal economy; limited education and training opportunities; increasing demand for low cost goods and services; and migration motivated by economic hardships and poverty. (p. 17)

\section{Transitioning from the informal to the formal sector}

When businesses transition from the informal to the formal sector, they could experience several challenges. In research conducted in Bloemfontein, South Africa (Tassin 2014), the following challenges were evident in transitioning from an informal to a formal business: lack of information and limited skills, regulatory barriers, administrative barriers, financial requirements and business fees, corruption, fear of the unknown and smallness of the business. Tassin (2014:43) emphasised that the lack of proper information on government support agencies put in place to assist small enterprises in the informal sector to become formal is a great impediment to formalisation'. Without access to proper information, the informal craft traders in Tembisa would not be able to transition to formal businesses. Regulatory barriers refer to regulations that are restricting new entrants or those transitioning from the informal to the formal sector (Banda, Robb \& Roberts 2015). Administrative barriers include long queues to obtain forms and excessive paperwork to formalise their business (Tassin 2014:44). The size of the business can have an impact on the success of the transition. Stakeholders can play a supporting role in assisting these informal and small businesses in making their transition. These stakeholders include the government, government entities, the private sector and non-governmental organisations. According to the findings by Tassin (2014:62), some of the factors that have contributed to the transition are 'growth and expansion, access to proper banking services, government contracts and tenders, access to bank loans and trust from customers/ suppliers'.

Research conducted by Banda et al. (2015b) through the Centre for Competition, Regulation and Economic Development showed that securing financial support for the business is the main challenge to transition to the formal sector. Once funding has been obtained, the authors found that it is incorrectly used. To avoid the misuse of funding, they suggest that training in communication, negotiation and other entrepreneurial skills, together with development finances, be offered to these entrepreneurs.

The access to market is critical to reach adequate numbers of potential consumers (Banda et al. 2015a). To overcome this barrier, support in identifying potential consumers and marketing to these consumers should be provided (Banda et al. 2015a). This is of particular relevance to the informal craft traders in Tembisa. The representative of Ekurhuleni
Department of Economic Development (DED) indicated that they facilitate such processes but they have not facilitated one specifically for craft traders.

\section{Ekurhuleni Metropolitan Municipality support for empowering women in art}

The municipality will grant free use of facilities for art-related events (Ekurhuleni Metropolitan Municipality 2006 s 2A(11)). This means that events such as art seminars, exhibitions and training can take place at these facilities within the municipality for free. In addition (Ekurhuleni Metropolitan Municipality 2006):

[C]ommunity Art Centres are facilities that offer the community opportunities for informal and formal arts education and training: participation in cultural activities and access to resources for artistic and economic empowerment: while this community is significantly represented and influential in its own governance management. (5 s B(1)(1)).

The extent to which informal craft traders such as those selling woven baskets and beaded accessories can benefit from these by-laws has not been investigated.

In summary, little is known about the women who sell crafts in Tembisa, trading in the informal sector. Literature has revealed that the majority of informal traders in South Africa are women from poor communities.

The primary objective of this study was to investigate the business model used, skills needed by and opportunities and support measures available to the women informally trading craft ware in Tembisa to empower them to move from the informal to the formal sector.

\section{Research methodology and design}

A descriptive and exploratory research with pragmatism as research philosophy resulted in a concurrent mixed-methods research (Edmonds \& Kennedy 2010:12; Saunders, Lewis \& Thornhill 2009:109). For the quantitative part of the study, a survey using a structured questionnaire was conducted to collect data from craft traders who make and sell woven baskets and accessories in the Tembisa community. The questionnaire was reviewed by the supervisor and statistician, pilot-tested, revised and then approved. The exact number of craft traders within Tembisa was unknown at the start of the study. Women traders between 18 and 65 years of age who consented to participate were included in the survey. As the study strictly focused on women, 32 craft traders selling accessories and baskets participated in the study. The participants were from different areas within Tembisa.

For the qualitative part, the study aimed to interview three organisations: the Ekurhuleni DED, the Moses Molelekwa Centre and the Ekurhuleni Department of Sports, Arts, Culture and Recreation. Only the first two organisations were interviewed, as no official from Ekurhuleni Department of Sports, Arts, Culture and Recreation was available to participate, despite repeated requests. In addition, 
Ekurhuleni Metropolitan Municipality documents were scoured for evidence of the municipality's performance in terms of projects and programmes empowering its women entrepreneurs.

\section{Research results from survey respondents (craft traders) Demographics of the respondents (women craft traders)}

This section focuses on presenting and interpreting the demographic information of respondents participated in this study, who are informal traders from Tembisa township.

From the quantitative survey, the majority $(84 \%)$ of the 32 respondents were non-South Africans, with only $16 \%$ South African. The foreigners are nationals from the following countries: Zimbabwe, Lesotho, Swaziland and Mozambique, all bordering on South Africa. More than half (59\%) of the respondents can be classified as youth, between the ages of 18 and 35 years, whilst $41 \%$ were between 36 and 65 years. It follows that some foreign youths use weaving as a form of employment. Foreigners entering into the informal sector can be attributed to the 'costs and regulatory barriers of entry into the formal economy; limited education and training opportunities; [and] increasing demand for and migration motivated by economic hardships and poverty' (Ndabeni \& Maharaj 2013:17).

All the respondents had dependents, with $47 \%$ of the respondents responsible for one or two dependents, whilst a further $47 \%$ support between three and five dependents and $6 \%$ support as many as six or seven dependents. Of the five South African respondents, four had secondary and one had a tertiary level of education. The majority (16) of the nonSouth Africans have secondary education, whilst five have primary level education and six have no education. Thus, $63 \%$ of all the respondents have secondary education.

\section{Nature of the informal craft businesses}

The respondents indicated that the weaving business is seasonal. In the case of baskets, the straw used for weaving is not available throughout the year but only sufficient after the rainy season. At the time of collecting data (September and August), there was a shortage in the supply of straw, resulting in only seven of the respondents having baskets for sale. Most respondents sell baskets as well as African accessories. Of the 32 respondents, 25 sell only accessories, whilst only 7 respondents sell baskets; and of these 7 , only 5 sell both baskets and accessories, which means that 30 respondents sell accessories.

The respondents sell a variety of woven art products. The straw Basotho mat and small broom are used when selecting beans (Figure 1a). The mantji [baskets] are made by the Swati people and used to carry fruits and vegetables (Figure 1b). A similar basket is popularly used in the home for fruit storage (Figure 1c).

The laundry baskets are available all year round and are typically woven by men and sold by women (Figure 2). These baskets are made from old drainage pipes heated over fire. The softened plastic is stretched into long strings for weaving.

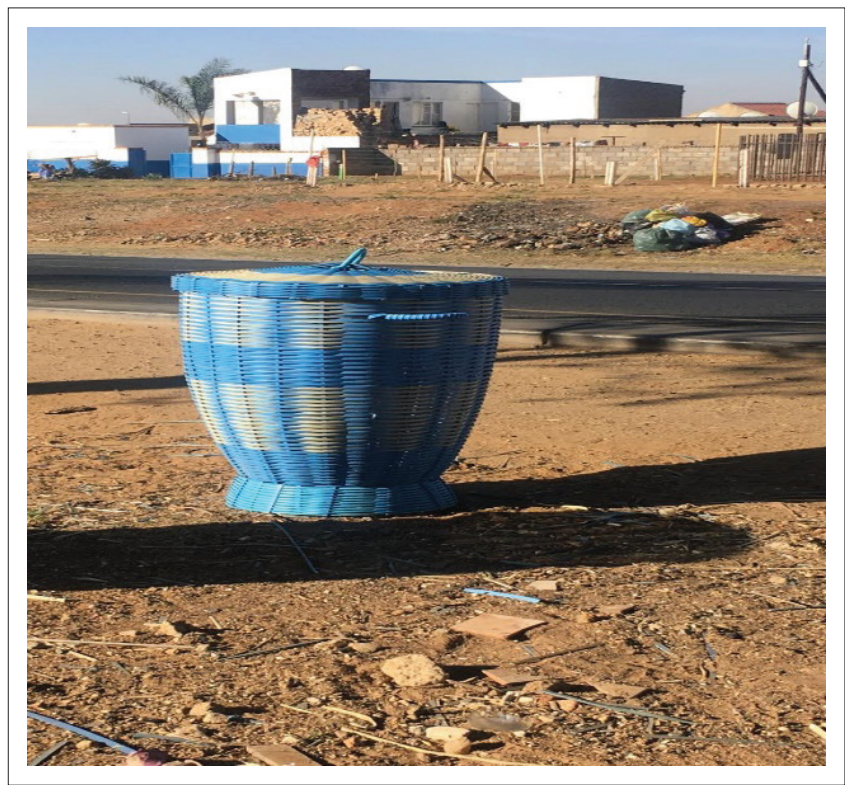

Source: Photo taken by the author.

FIGURE 2: Laundry baskets made from drainage pipes sold by respondents.
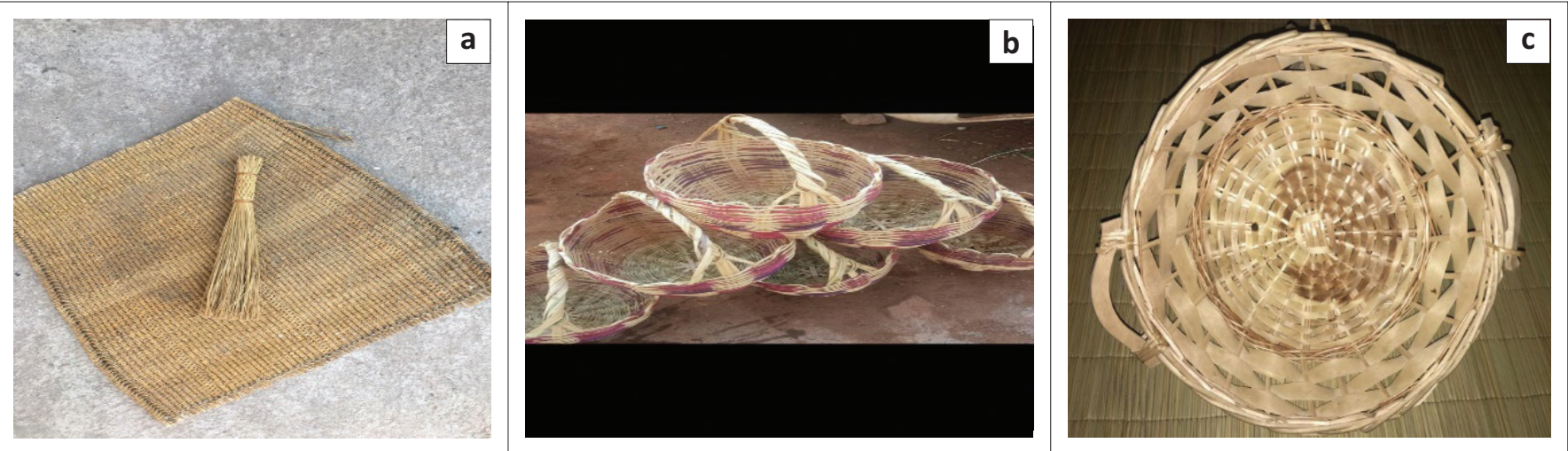

Source: Photos taken by the author.

FIGURE 1: Woven art products. (a), The straw Basotho mat and small broom used when selecting beans; (b), The mantji [baskets] made by the Swati people and used to carry fruits and vegetables, and (c) a similar basket used in the home for fruit storage. 
A few African accessories, such as the Basotho hats, are woven from straw (Figure 3). The one on the left is for an adult and the unfinished one on the right is for a child.

The respondents sell a range of traditional accessories made primarily from beads (Figure 4).

The majority of the customers of the respondents are community members. Of the 32 respondents, 10 respondents sell their products door to door, whilst 17 respondents sell at street corners or taxi ranks. The five South African respondents ( $16 \%$ of the sample) sell their crafts to the local art centre.

According to the respondents, the sales of these art-and-crafts products are irregular and tend to be seasonal. All the respondents highlighted that sales of accessories are higher between September and December and again in March and April. They ascribe it to September being Heritage Month in South Africa and the increase in weddings during the warmer months of December, March

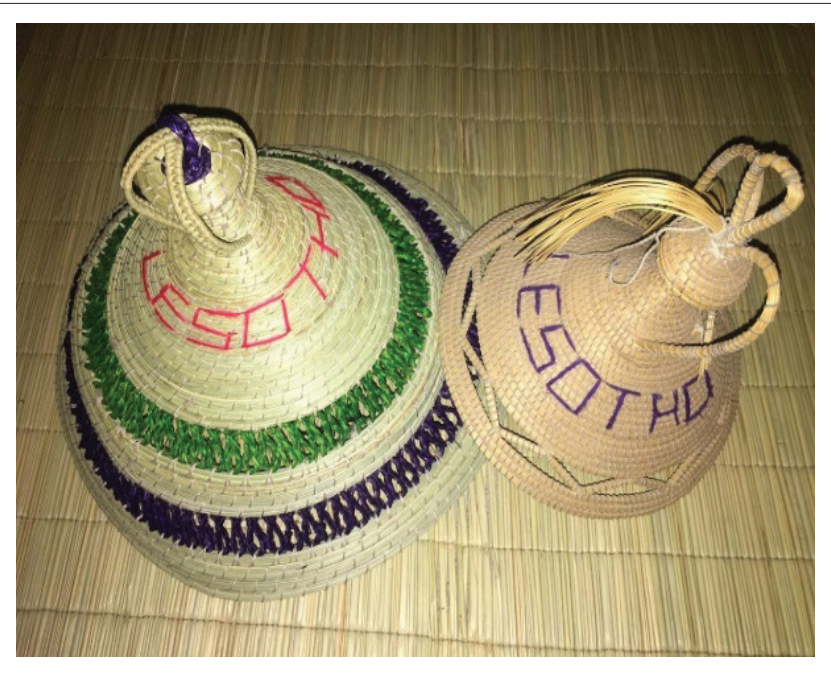

Source: Photo taken by the author.

FIGURE 3: Mokorotlo and modiyanyeo - Basotho hats - sold by respondents. and April. Respondents noted that the data-collection period (August and September) was the 'good season', as they had started receiving orders from clients for the week of Heritage Day.

The respondents spend between 5 and 7 days a week selling their products. There seems to be a direct and positive relationship between the number of days respondents operate and the income they receive per week (Table 1).

The 15 respondents who earn between R501 and R1000 per week sell for only 5 days per week, whilst 8 of the 13 respondents who earn between R1501 and R2000 per week operate for 6 days. Seven operate for 7 days per week (Table 1). A further four respondents who operate 7 days per week earn more than R2000 per week. Respondents who sell their products on weekends explained that most of their clients work during the week and can only purchase over weekends.

\section{Skills training requirements of respondents}

This section focuses on the different skills that the respondents possess and their skills training requirements. The skill of weaving can be acquired from formal and informal educational settings. Of the 32 respondents, 17 weave their own crafts. They learnt the skill of weaving from friends, family (mothers and grandmothers were mentioned by most respondents) and at school. Only two of the five South Africans weave the products they sell and learnt the skill of weaving at school. The other three South Africans buy the woven products to sell. This supports findings by Hunter and Skinner (2001) that some foreigners have been

TABLE 1: Relationship between number of days selling and income per week.

\begin{tabular}{lccccc}
\hline $\begin{array}{l}\text { No. of days } \\
\text { selling }\end{array}$ & R0-R500 & R501-R1000 & $\begin{array}{c}\text { R1001- } \\
\text { R1500 }\end{array}$ & $\begin{array}{c}\text { R1501- } \\
\text { R2000 }\end{array}$ & $\begin{array}{c}\text { More than } \\
\text { R2000 }\end{array}$ \\
\hline 5 days per week & - & 15 & - & - & - \\
6 days per week & - & - & - & 8 & - \\
7 days per week & - & - & - & 5 & 4 \\
\hline Total & - & $\mathbf{1 5}$ & - & $\mathbf{1 3}$ & 4 \\
\hline
\end{tabular}

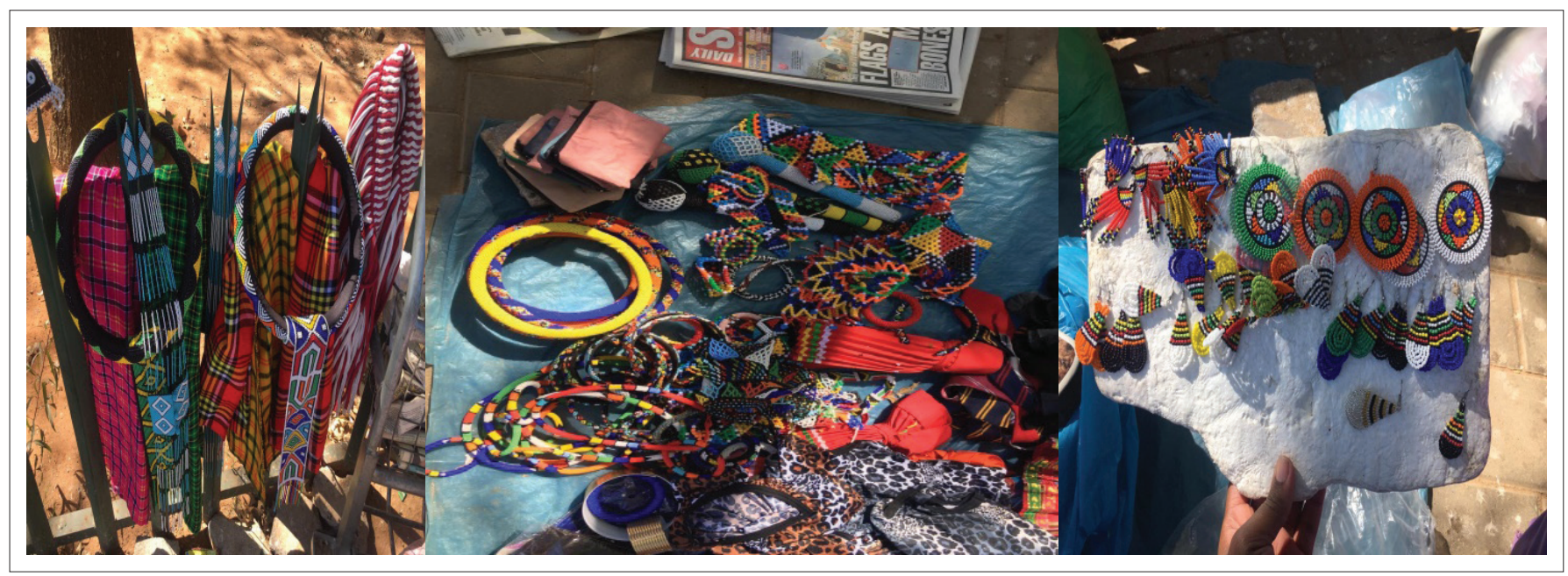

Source: Photos taken by the author.

FIGURE 4: Accessories sold by the respondents. 
trained in their home country, and the possibility therefore exists for skills to be transferred from these foreign traders to the local people. One of the respondents of the study indicated that they would like to teach young people in South Africa how to do craft work. Most of these respondents say they require training in entrepreneurial skills (94\%), communication skills (97\%) and negotiation and networking skills (97\%) (Table 2). Only the two South Africans had received training. DSBD (2017) highlighted that such training will uplift respondents and can result in informal businesses realising the benefits of transitioning, where they will be able to benefit from the incentives and small and medium enterprise programmes.

\section{Transitioning from informal to formal business: respondents' views}

Of the 32 respondents, $66 \%$ would like to grow their businesses. However, they identified several challenges preventing them from doing so (Table 3). For the 21 respondents who want to grow their businesses, the two main challenges are limited skills (62\%) and lack of information (48\%). This is in line with the finding of Tassin (2014) that lack of information on the type of support that is available for informal traders weakens or discourages the informal traders' interest in transitioning into the formal sector.

Even though most of the respondents are foreigners, only $24 \%$ found language to be a barrier to growth. Only $24 \%$ of these respondents identified finances as a challenge. It appears that the language used to communicate information about transitioning is not a problem for most of these respondents. Perhaps the challenge lies in the information itself. Ndabeni and Maharaj (2013) found that limited education and training opportunities are some of the barriers to business growth. This highlights the importance of education to ensure that participants fully understand what is presented to them.

TABLE 2: Types of skills development training received and required by respondents.

\begin{tabular}{lccc}
\hline Type of skill & Received training & \multicolumn{2}{c}{ Require training } \\
\cline { 3 - 4 } & & $\boldsymbol{n}$ & $\mathbf{\%}$ \\
\hline Entrepreneurial skills & 2 & 30 & 94 \\
Communication skills & 1 & 31 & 97 \\
Negotiation or networking skills & 1 & 31 & 97 \\
\hline
\end{tabular}

TABLE 3: Barriers to business growth by respondents who want business growth.

\begin{tabular}{lcc}
\hline Type of challenge & $\begin{array}{c}\text { No. of respondents experiencing } \\
\text { the challenge }(\boldsymbol{n}=\mathbf{2 1})\end{array}$ \\
\cline { 2 - 3 } & $\boldsymbol{n}$ & $\%$ \\
\hline Limited skills & 13 & 62 \\
Lack of information & 10 & 48 \\
Language barriers & 5 & 24 \\
Other - financial challenges & 5 & 24 \\
Regulatory barriers & 0 & - \\
Administrative barriers & 0 & - \\
Corruption & 0 & - \\
Business fees (registration fees) & 0 & - \\
Infrastructure to store goods & 0 & - \\
\hline
\end{tabular}

Although respondents did not identify finances as a challenge, all 21 respondents identified financial support as the most crucial type of support they need to grow their business, whilst $41 \%$ want support in the form of skills development, in particular entrepreneurial education and training.

\section{Reasons for reluctance to grow the business: 11 respondents}

Eleven (34\%) of the respondents indicated that they would not like to grow their businesses. Of the 11 respondents, eight indicated that they were satisfied with the size of their business, whilst three explained that they do not want to pay business fees, and two stated that they are seeking employment. The latter is supported by Anele Horn (2011) who stated that because of the high rate of unemployment in the country, many have resorted to seeking employment in the informal sector.

\section{Formalisation, collaboration and partnerships: Respondents' perspectives}

This study investigated respondents' opinions towards formalisation, collaboration and establishing partnerships. Of the 32 respondents, none are part of a cooperative, nor would like to be part of one. Of the non-South Africans, eight have formed a group to support each other and to enable all group members to send money to families regardless of sales. Respondents who are not part of a group indicated that they do not want to be part of one. Only two respondents indicated that they are interested in establishing a partnership with an agent, whereas two other respondents said they are interested in collaborating with a distributor who would ensure that their crafts reach more customers.

The majority $(78 \%)$ of the respondents do not want their business to be formal, stating that the formalisation of their business will restrict the flexibility of their business. They indicated that there is excessive paperwork involved in the process and the transition will mean they have to pay registration fees. The $22 \%$ of respondents who would like to transition from the informal to the formal sector foresee benefitting from the opportunities available to formal businesses.

\section{Findings from the relevant departments}

Interviews were conducted with the representatives of Ekurhuleni DED and the Moses Molelekwa Centre during September.

\section{Ekurhuleni Department of Economic Development}

At the Ekurhuleni DED, the business compliance and regulations manager was interviewed to determine whether the DED is implementing programmes for women in business. He has been with the DED since 01 October 2013, and he 
explained that the Ekurhuleni DED has the following programmes that include women: mentorship, incubators, innovation hubs and the informal trade programme. The latter includes both men and women, with $60 \%$ representation by women. The informal trade programme focuses on hawkers, spaza shops and any form of business operating in the informal sector. The Ekurhuleni DED informal trade programme offers respondents transitioning support by ensuring their applications meet all compliance requirements, and that they have the required business permits and permission to use their chosen location, and by assisting them with business registration. In Ekurhuleni, the DED holds road shows to inform the community of these programmes, and these are open to all nationalities, not only South Africans. Respondents can benefit from these programmes.

The manager stated that the Ekurhuleni DED only assists those who approach it and seek assistance. The interviewee added that when implementing these programmes, the Ekurhuleni DED promotes entrepreneurship through introducing the business owners to cooperatives and assisting them to formalise their business so that they are able to seek and apply for opportunities.

The manager added that the Ekurhuleni DED is establishing a directorate focussing on supporting women in business by assisting them to legitimise and formalise their businesses, and promoting access to the markets through enterprise development support.

\section{Moses Molelekwa Centre}

According to the centre manager, the Moses Molelekwa Centre offers the Tembisa residents a facility where they can showcase their talents. He added that the centre provides a venue for art-related festivals and hosted the Ekurhuleni Public Art Exhibition in 2016. According to the centre manager, who has been with the centre since 2006, the centre is one of the five art centres in Ekurhuleni. It promotes entrepreneurship through events. Whenever there is an event at the centre, artists are offered the opportunity to sell their art and crafts. The Kuwamba Women's Arts Festival was launched in 2015 and had more than 300 participants at the time of writing.

The art centre manager argues that economic empowerment uplifts people by offering skills development and offering them support to make a living or an income. The skills development and support offered should ensure that the recipients are able to sustain the initiative they have started to earn an income. The centre's programmes achieve and promote economic empowerment by allowing participants to earn an income and encourage them to further their studies.

The majority of programme participants use the money to further their studies. The programme has produced professional art crafters. In addition, the centre has started a 2-weekly flea market in the Tembisa suburb of Sethokga, where crafters are allowed to exhibit and sell their wares.

\section{Conclusion and recommendations}

The primary objective of this article was to investigate the business model used, skills needed by and the local opportunities and support measures available to the women trading their crafts informally in Tembisa to empower them to transition into the formal craft traders. An unexpected finding was that the majority of the $32 \mathrm{craft}$ traders are nonSouth Africans and youth (18-35 years of age). The question arises as to why so few South Africans use the skill of basket weaving and traditional beading as a form of employment? This would need further investigation. At the time of data collection, few were selling baskets and other woven products, owing to a shortage in raw material (straw for weaving). This led to some weavers exploring the use of other materials.

\section{Business model used}

The respondents are mostly street vendors, with a few selling door to door. Those who are street vendors do not move around but locate themselves at a specific spot, so that potential customers would know where to find them. There is a correlation between the number of days spent selling and income. Those who sell 7 days per week earn a higher income than those who only sell for 5 or 6 days. Respondents who are open for business on weekends accommodate customers who work during the week and can only shop on weekends. Respondents did not indicate how the prices of the crafts are determined; however, the prices they charge are similar. Three-quarters of the respondents are not willing to transition from an informal to a formal business. Their reasons are that their revenue is irregular and they need flexibility in the business. The reluctance to formalise may be linked to the fact that they are mostly non-South Africans.

\section{Skills required}

The respondents tended to have limited education. Only 1 respondent has a tertiary education, 20 have secondary level of education, 5 attended primary schools and 6 respondents do not have any formal education. This low level of education may be another reason contributing to the reluctance to formalise the business.

Respondents have indicated that they would like to receive financial support, skills development and entrepreneurial education and training. Despite the reluctance to transition to the formal sector, the respondents would like to grow their business, so that their revenue can increase. They noted that they believe that the aforementioned skills will contribute to the growth of their business.

\section{Economic empowerment}

The Ekurhuleni Metropolitan Municipality has welldeveloped programmes that focus on informal traders. However, these programmes do not specifically cater for or focus on informal craft producers and traders. Support measures and sources of funding are available in the local 
community to assist informal craft sellers. The Ekurhuleni DED has programmes that are inclusive of women and nonSouth African nationals, and these address the needs of those who would like to transition to the formal sector. The Ekurhuleni DED does not approach or identify individuals or groups that need assistance, rather requiring those who do to approach it. The Ekurhuleni DED does, however, host road shows to inform the communities about these programmes and plans to establish a directorate that will focus on ensuring that more women operate their business in the formal sector.

The programmes at the Moses Molelekwa Centre are inclusive of women but only for South Africans. The centre does not have programmes that focus on the business process of transition into the formal sector. The centre's programmes are dependent on the support of sponsors.

\section{Recommendations and future research}

The Ekurhuleni DED and the Moses Molelekwa Centre should collaborate and develop empowerment programmes that will include informal women craft traders. The Ekurhuleni DED should create programmes that not only promote the transition process to the formal sector, but also focus on assisting the informal traders to grow their business without enforcing the transitioning process. Once the businesses are established and are making sufficient turnover, the process of transitioning could be introduced.

The Moses Molelekwa Centre could form a partnership with the traders, allowing them to do business at its premises. This will ensure that potential customers know where to go when they want to purchase crafts.

Future research should focus on a much larger sample with mostly South African informal women craft traders to determine their awareness of skills development programmes and challenges in participating in such programmes.

\section{Acknowledgements Competing interests}

The authors have declared that no competing interests exist.

\section{Authors' contributions}

All authors contributed equally to this work.

\section{Ethical consideration}

Ethics clearance was provided by the School of Economics, University of Johannesburg. Ethical clearance number: 2018CENLED04.

\section{Funding information}

This research received no specific grant from any funding agency in the public, commercial or not-for-profit sectors.

\section{Data availability statement}

Data sharing is not applicable to this article as no new data were created or analysed in this study.

\section{Disclaimer}

The views and opinions expressed in this article are those of the authors and do not necessarily reflect the official policy or position of any affiliated agency of the authors.

\section{References}

Banda, F., Robb, G. \& Roberts, S., 2015a, The links between competition policy, regulatory policy and trade and industrial policies, CCRED and University of
Johannesburg, viewed 15 March 2018, from http://www.competition.org.za/s/ Johannesburg, viewed 15 March
Reviewpaper2draft_28042015.pdf

Banda, F., Robb, G., Roberts, S. \& Vilakazi, T., 2015b, Key debates in competition, capabilities development and related policies: Drawing the link between barriers to entry and inclusive growth, CCRED and University of Johannesburg, viewed $15 \mathrm{March} 2018$, from https://static1.squarespace.com/static/52246331e4b0a46e5f1b8ce5/t/ 5890552 f44024360fd1ccbod/1485854004101/Review\%2Bpaper\%2B1_\%2B28\%2BA pril.pdf

Brody, C., De Hoop, T., Vojtkova, M., Warnock, R., Dunbar, M., Murthy, P. et al., 2015, Economic self-help group programs for improving women's empowerment: A systematic review, Campbell Systematic Reviews, The Campbell Collaboration, Philadelphia, CA.

Chen, M.A, 2012, 'The informal economy: Definitions, theories and policies', WIEGO Working Paper No 1, viewed 25 April 2018, from http://www.wiego.prg/sites/ default/files/publications/files/chen_wiego_wp1.pdf

CoGTA, 2009, 'State of local government in South Africa', Working document: National state of local government assessments, Government Printer, Pretoria.

CoGTA, 2017, National policy framework for local economic development: Creating innovation-driven local economies 2017-2022, CoGTA, Pretoria.

Cohen, D. \& Horn, P., 2012, 'Raising the profile of the informal trade management as a key municipal service delivery function', presentation at the KwaZulu-Natal 2012 Regional and Local Economic Development Summit, viewed 04 June 2018, from http://gijima.kznded.gov.za/Uploads/DownloadDocuments/SALGA_STNET_KZN_ LED.pptx

Department of Arts and Culture, 2011, Strategic plan 2011-2016, Department of Arts and Culture, Pretoria.

Department of Arts and Culture, 2016, Pocket guide to South Africa 2014/15, Department of Arts and Culture, Pretoria.

DSBD, 2017, Presentation by the Department of Small Business Development: Informal business support, viewed 02 July 2018, from http://www.mile.org.za/QuickLinks/ News/ILO\%20Workshop\%20Presentations/R204\%20DSBD\%2023052017.pptx

DTI, 2006, Draft strategic framework on gender and women's economic empowerment, DTI, Pretoria.

Edmonds, W.A. \& Kennedy, T.D., 2010, A visual guide to basic research design: A visua system for research designs in education and the social \& behavioural sciences, Pearson Learning Solutions, New York, NY.

Ekurhuleni Metropolitan Municipality, 2006, By-laws for arts, culture and heritage facilities, viewed 16 April 2018, from http://www.ekurhuleni.gov.za

Ekurhuleni Metropolitan Municipality, 2017, Integrated development plan (IDP) of City of Ekurhuleni 2017/18 to 2020/21, viewed 15 March 2018, from http://www. City of Ekurhuleni
ekurhuleni.gov.za

Fredericks, N., 2014, Small business connect, Department of Trade and Industry, viewed 02 July 2018, from http://www.smallbusinessconnect.co.za/news/ informal-businesses-get-help.html\#.WzoORzSxWEc

Gauteng Organisation of Community Arts and Culture Centres, 2010, History of GOMACC: Our focus, viewed 15 March 2018, from http://www.gomacc.org.za/ about.html

Horn, A., 2011, 'Who's out there? A profile of informal traders in four South African city central business districts', Town and Regional Planning 59, 1-6, viewed 20 March 2018, from http://journals.ufs.ac.za/index.php/trp/article/view/484/464

Hunter, N. \& Skinner, C., 2001, Foreign street traders working in inner city Durban: Survey results and policy dilemmas, School of Development Studies, University of Natal, Durban.

Ilala Weavers, 2018, The baskets, viewed 20 April 2018, from http://www.ilala.co.za/ about-us/baskets.html

Malema, D.R. \& Naidoo, S., 2017, 'Spaces for the empowerment of women: Rural arts and craft projects', African Journal of Hospitality, Tourism and Leisure 6(2), 1-18, viewed 28 July 2019 from http://www.ajhtl.com/uploads/7/1/6/3/7163688/ article_9_vol_6_2_2017.pdf

McLachlan, G., 2005, 'Wire craft and urban space: A case study of the informal wire art trade in South Africa', presentation at 41st ISoCarp Congress, viewed 28 April 2020, from http://www.isocarp.net/Data/case_studies/583.pdf

Meyer, D.F., 2014, Local economic development (LED), challenges and solutions: The case of the Northern Free State region, South Africa, viewed 23 September 2018 from https://showme.co.za/vaal/files/2014/08/Local-economic-developmentLED-challenges-and-solutions.pdf 
'Moses Molelekwa Arts Centre hosts art exhibition', in Kempton Express, 21 July, 2016 , viewed 15 March 2018, from https://kemptonexpress.co.za/266171/harambeebrt-creates-jobs-for-artists-2

National Planning Commission, 2011, National development plan vision 2030, The Presidency of the Republic of South Africa, Pretoria.

Ndabeni, L.L. \& Maharaj, R., 2013, 'The informal sector and the challenges of development in South Africa', paper presented at Human Development and Knowledge Economy Conference, Patiala, India, viewed 28 April 2020, from https://ieri.org.za/sites/default/files/outputs/informal_sector_and the challenges_of_development_in_south_africa.pdf

Nettleton, A., 2010. 'Life in a Zulu village: Craft and the art of modernity in South Africa', The Journal of Modern Craft 3(1), 55-78. https://doi.org/10.2752/174967 $810 \times 12657245205189$

Nyawo, J. \& Mubangizi, B.C., 2015, 'Art and craft in local economic development: Tourism possibilities in Mtubatuba Local Municipality', African Journal of Hospitality, Tourism and Leisure 4(2), 1-15.

Rogerson, C.M., 2009, 'Strategic review of local economic development in South Africa', Development Southern Africa 27(4), 481-495. http://doi.org/10.1080/037 6835X.2010.508580

Saunders, M.N.K., Lewis, P. \& Thornhill, A., 2009, Research methods for business students, Financial Times, Harlow.
Statistics South Africa, 2015, National and provincial labour market: Youth, viewed 23 April 2020, from https://www.statssa.gov.za/publications/P02114.2/ P02114.22015.pdf

Swinburn, G., Goga, S. \& Murphy, F., 2006, Local economic development: A primer developing and implementing local economic development strategies and action plans, The World Bank, Washington, DC.

Tassin, R.E.N., 2014, 'Transiting from the informal to formal business: Motives, challenges and the coping mechanisms of selected transited businesses in the Bloemfontein area', Master's dissertation, Faculty of Management Sciences, Central University of Technology, Free State.

The South African Craft Industry, 1998, Cultural industries growth strategy (CIGS), viewed 27 July 2019, from https://www.gov.za/sites/default/files/gcis document/201409/cigs0.pdf

United Nations Conference on Trade and Development, 2017, UNCTAD handbook of statistics 2017 - Population, fact sheet \#12: Age structure, viewed 08 Septembe 2020, from https://unctad.org/en/PublicationChapters/tdstat42_FS12_en.pdf

Venter, M., 2014., 'From lip-service to service delivery in local economic development: Guidelines to set up an agency for action', Journal of Economic and Financial Sciences 7(3), 721-736. https://doi.org/10.4102/jef.v7i3.235

Zungu, B.P.K., 2000, 'Meaning behind the use and wearing of traditional beadwork at Msinga area', Master's dissertation, Faculty of Arts, University of Durban-Westville. 